\title{
María Estela Guevara de Álvarez y María Guadalupe Barandica (Coordinadoras). Sentencias de Esquilo. Buenos Aires: Teseo Press, 2020
}

\author{
Maria Luz Mattioli \\ Universidad Nacional de La Plata, Argentina \\ luz.mattioli@gmail.com \\ iD http://orcid.org/0000-0002-5242-031X
}

La antología Sentencias de Esquilo ha sido publicada recientemente por un equipo de profesores de la Facultad de Filosofía y Letras de la Universidad Nacional de Cuyo (Mendoza, Argentina). Este libro constituye la cuarta parte de la Antología gnómica de la literatura griega, que reúne el repertorio de sentencias de la poesía épica, lírica y dramática según un orden cronológico de autores. Después de los volúmenes dedicados a Homero y Hesíodo, a los poetas elegíacos y yambógrafos y a los poetas monódicos y corales los autores centran su atención en el primero de los trágicos, Esquilo.

El volumen resulta por demás interesante no sólo a los efectos de la investigación enmarcada en el drama de Esquilo, sino también porque reviste un carácter ampliamente didáctico que posibilita a estudiantes y alumnos acceder a un material novedoso y reciente, ya que, por un lado, se detiene en la tragedias conservadas del dramaturgo y propone un análisis pormenorizado de ellas; por otro lado, a partir del análisis filológico,captura uno de los aspectos centrales de la tragedia esquilea: el uso de la sentencia. La lectura de este volumen de acceso abierto se puede hacer ingresando en https://www.teseopress.com/sentencias/fron $\mathrm{t}$-matter/sin_titulo/.

Sentencias de Esquilo se compone de una "Introducción" (pp. 9-16) en la que se delimita la manera de abordar los textos y también se definen los conceptos matrices que son transversales a todo el volumen. En la página 17 se especifican los nombres de los autores a cargo de cada una de las tragedias y, luego, encontramos el cuerpo de la antología ordenada bajo un criterio cronológico. En primer lugar, el estudio de las sentencias en Persas (pp. 21-26) por M. L. Orozco; Siete contra Tebas (pp. 27-37) a cargo de S. Aguirre de Zárate y Suplicantes (pp. 39-50) por E. Driban. A continuación, M. G. Barandica se ocupa del capítulo dedicado a Agamenón (pp. 51-76); Coéforas (pp. 77-86) está a cargo de P. Arias; M. C. López se ocupa del capítulo dedicado a Euménides, y M. E. Guevara de Álvarez a Prometeo Encadenado (pp. 99-108). La segunda parte de la Antología está dedicada al análisis de los Fragmentos conservados (pp. 109-126). A. Salomón analiza los “Fragmentos 1-10” y M. E. Guevara de Álvarez los “Fragmentos 11-45”. Finalmente, los lectores podrán encontrar un "Índice temático" en el que se da ingreso a las sentencias catalogadas según temas y subtemas, lo que permite el acceso a las gnômai en forma independiente de su identificación por tragedia (pp. 127-132) y la "Bibliografía" (pp. 133-138).

La "Introducción” del volumen a cargo de M. Estela Guevara de Álvarez es central para comprender la totalidad de la Antología. En primer lugar, la autora propone un recorrido por la biografía de Esquilo y sostiene que las sentencias esquileas son -a diferencia de la poesía precedente- de sentido profundo y de difícil significado, poco adecuadas para repetirse de boca en boca al modo de los proverbios (p. 11). Por otro lado, y esto resultará clave en la tragedia de Esquilo, señala también las diferencias de empleo con las gnômai homéricas, ya que Esquilo elige a quién hace decir cada gnômai. A nivel cuantitativo, Guevara de 
Álvarez explica que el estudio de las gnômai en la obra de Esquilo permite identificar un total de doscientas cuarenta y tres sentencias, distribuidas del siguiente modo: diez sentencias en Persas, veintiséis en Siete contra Tebas, treinta y cuatro en Suplicantes, sesenta en Agamenón, veintidós en Coéforas, veinticuatro en Euménides, veintidós en Prometeo encadenado y cuarenta y cinco en los Fragmentos (p. 12).

$\mathrm{Al}$ momento de proponer el análisis filológico, la autora explica los lineamientos sobre los cuales se ha construido este volumen y cómo se ha ordenado el material. En cada uno de los capítulos dedicados a las tragedias de Esquilo se presenta el argumento de la obra y luego se enumeran las sentencias. Así, por ejemplo, la sentencia número cuatro de Persas se presenta del siguiente modo:

Pers. vv. 689-690. La sombra de Darío al Coro de ancianos persas.

Los dioses subterráneos son mejores en tomar que en soltar

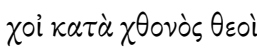

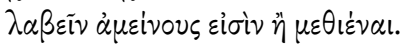

689 xoỉ Crasis ática de kaì oi

El lector podrá encontrar, en primer lugar, la referencia a la tragedia y los versos específicos de la sentencia analizada. En segundo lugar, aparece la sentencia en español y luego la sentencia en lengua griega que corresponde a las ediciones de Smyth (1926) y Murray (1966). Por último, aparecen las notas en las que se aclaran cuestiones lingüísticas o comentarios que enriquecen la interpretación del texto.

Otro ejemplo que demuestra el trabajo minucioso que han realizado sobre el texto esquileo es la sentencia veintitrés de Suplicantes de Esquilo que citamos a continuación:

Supp. vv. 760-761. Dánao al Corifeo.

Hay un dicho: los lobos son más fuertes que los perros.

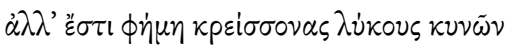

$\varepsilon \tilde{\nu} \alpha \mathrm{ll}$

760-761 Si los egipcios son perros, los argivos son lobos. Debe notarse que el llamar a una persona 'lobo' no constituía un insulto entre los griegos; un testimonio es el nombre Lykos (Rose). El perro era en Egipto objeto de veneración profunda;

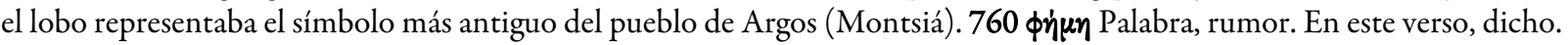

Como ya hemos mencionado, la última parte del volumen está dedicada a los Fragmentos. Los autores explican que, además de las tragedias completas, la tradición ha legado numerosos fragmentos atribuidos al poeta, clasificados en tres tipos: "Fragmentos de obras conocidas" (Fragmenta certis fabulis adscripta); "Fragmentos de lugar desconocido" (Incertarum fabulorum fragmenta) y, por último, "Fragmentos dudosos" (Fragmenta dubia). Esa será la clasificación que seguirán los autores para analizar las sentencias. Así, por ejemplo, dentro del grupo "Fragmentos de obras conocidas" presentan la sentencia once del "juicio de las armas":

11)El juicio de las armas, frg. 176 v. 1 Estobeo III 11, 14.

Las palabras de la verdad son simples.

$\dot{\alpha} \pi \lambda \tilde{\alpha} \gamma \dot{\alpha} \rho \dot{\varepsilon} \sigma \tau \iota \tau \tilde{\eta} \varsigma \dot{\alpha} \lambda \eta \theta \varepsilon \dot{i} \alpha \varsigma^{\ddot{\varepsilon} \pi \eta \eta}$

1 Verso atribuido a Áyax. Esta gnóme, que pondera la llaneza de la verdad, se registra con leve variante en Apostolio III 60k (CPG): $\dot{\alpha} \pi \lambda \tilde{\alpha} \gamma \dot{\alpha} \rho \dot{\varepsilon} \sigma \tau \iota \tau \tilde{\eta} \varsigma \dot{\alpha} \lambda \eta \theta \varepsilon \dot{\alpha} \alpha \varsigma \tau \ddot{\alpha} \pi \eta$.

A modo de conclusión, creemos que es muy valioso el aporte que supone la Antología Sentencias de Esquilo, ya que propone un recorrido por la tragedia esquilea tanto para quienes conocen la lengua griega y al 
dramaturgo, como así también para quienes deseen comenzar a transitarla, poniendo el foco de atención en el repertorio gnómico. La relevancia de las gnômai en Esquilo resulta expresada de modo cabal, en las propias palabras de los autores:

El material gnómico conservado descubre las grandes inquietudes que recorren la obra de Esquilo. Allí están los poderes que fijan el ordenamiento del mundo, la irrevocabilidad de las leyes divinas, la dignidad del hombre superior, el riesgo de su caída, la relación entre culpa y desdicha. Y allí está su ética inexorable (p. 12).

\section{INFORMACIÓN ADICIONAL}

Recuperado de: https://www.teseopress.com/sentencias/front-matter/sin_titulo/ 